\title{
Efficient Utilization of Renewable Energy Sources by Gridable Vehicles in Cyber-Physical Energy Systems
}

\author{
Ahmed Yousuf Saber, Member, IEEE, and Ganesh Kumar Venayagamoorthy, Senior Member, IEEE
}

\begin{abstract}
The main sources of emission today are from the electric power and transportation sectors. One of the main goals of a cyber-physical energy system (CPES) is the integration of renewable energy sources and gridable vehicles (GVs) to maximize emission reduction. GVs can be used as loads, sources and energy storages in CPES. A large CPES is very complex considering all conventional and green distributed energy resources, dynamic data from sensors, and smart operations (e.g., charging/discharging, control, etc.) from/to the grid to reduce both cost and emission. If large number of GVs are connected to the electric grid randomly, peak load will be very high. The use of conventional thermal power plants will be economically expensive and environmentally unfriendly to sustain the electrified transportation. Intelligent scheduling and control of elements of energy systems have great potential for evolving a sustainable integrated electricity and transportation infrastructure. The maximum utilization of renewable energy sources using GVs for sustainable CPES (minimum cost and emission) is presented in this paper. Three models are described and results of the smart grid model show the highest potential for sustainability.
\end{abstract}

Index Terms-Cyber-physical energy systems, emission, gridable vehicles, load leveling, optimization, renewable energy, smart grid.

\section{NOMENCLATURE AND ACRONYMS}

$\begin{array}{ll}P_{\text {wind }}(t) & \text { Wind power at hour } t . \\ P_{\text {solar }}(t) & \text { Solar power at hour } t . \\ \mathcal{F C}() & \text { Fuel cost function. } \\ \mathcal{S C}_{i}() & \text { Start-up cost function of unit } i . \\ \mathcal{E C}_{i}() & \text { Emission cost function of unit } i . \\ N & \text { Number of units. } \\ H & \text { Scheduling period. } \\ I_{i}(t) & \text { On/off state of unit } i \text { at hour } t . \\ P_{i}(t) & \text { Output power of unit } i \text { at hour } t . \\ P_{i}^{\max / \min } & \text { Maximum/minimum output limit of unit } i .\end{array}$

Manuscript received June 15, 2009; revised March 17, 2010; accepted June 01, 2010. Date of publication August 19, 2010; date of current version September 01, 2010. This work was supported by the U.S. National Science Foundation (NSF) under NSF EFRI 0836017 and by CAREER Grant ECCS 0348221.

A. Y. Saber is with the Real-Time Power and Intelligent Systems Laboratory, Electrical and the uter Engineering Department, Missouri University of Science and Technology, Rolla, MO 65409-0040 USA (e-mail: aysaber@ ieee.org).

G. K. Venayagamoorthy is with the Real-Time Power and Intelligent Systems Laboratory, Missouri University of Science and Technology, Rolla, MO 654090040 USA (e-mail: gkumar@ieee.org).

Digital Object Identifier 10.1109/JSYST.2010.2059212

$\begin{array}{ll}D(t) & \text { Load demand at hour } t . \\ R(t) & \text { System reserve requirement at hour } t . \\ c / h-c_{i} t_{i} & \text { Cold/hot start cost of unit } i . \\ \mathcal{W}_{1}, \mathcal{W}_{2}, \mathcal{W}_{3} & \text { Weights of fuel cost, start-up cost and } \\ & \text { emission, respectively. } \\ \mathrm{S} 3 \mathrm{P} & \text { Small portable power plant. } \\ P_{v} & \text { Capacity of each vehicle. } \\ N_{V 2 G}(t) & \begin{array}{l}\text { Number of vehicles connected to the grid } \\ \text { at hour } t .\end{array} \\ N_{V 2 G}^{\max } & \text { Total registered GVs in the system. } \\ \mathrm{V} 2 \mathrm{G} / \mathrm{G} 2 \mathrm{~V} & \text { Vehicle-to-grid/grid-to-vehicle. } \\ r & \text { Particle number. } \\ j & \text { Dimension of the problem. } \\ k & \text { Iteration index. } \\ \delta & \text { Battery charging time. }\end{array}$

I. INTRODUCTION

W ITH increasing concern over global climate change, policy makers are promoting renewable energy sources (RESs) to meet emissions reduction targets. The alarming rate, at which global energy reserves are depleting, is a major worldwide concern at economic, environmental, industrial and community levels [1]-[4]. A partial solution to this crisis is (i) the use of decentralized renewable energy, and (ii) application of plug-in vehicles with vehicle-to-grid (V2G) capability reported to as "gridable vehicles" (GVs). GVs are modified version of plug-in hybrid electric vehicles (PHEVs) or electric vehicles (EVs) for next generation to spark a revolution in the energy and transportation industries. For economical importance, environmental impact and social motivation, new generation vehicles (i.e., gridable vehicles) should have the capability to charge/discharge from/to the grid respectively in an intelligent manner that utilizes RESs efficiently.

The use of renewable energy may become attractive, especially if, customers would have to pay not only for the cost of generation but also for transmission, distribution and the indirect cost of environmental cleanup and health effects [5]. Stimulated by recent technological developments, and increasing concern over the sustainability and environmental impact of fossil fuel usage, the prospect of producing clean and sustainable power in substantial quantities from RESs arouses interest around the world. Energy prices, supply uncertainties, 
and environmental concerns are driving the world to rethink its energy mix and develop diverse sources of clean, renewable energy. Researchers are working toward generating more energy from domestic resources that can be cost-effective and replaced or renewed without contributing to climate change or major adverse environmental impacts [6].

A technical report from National Renewable Energy Laboratory (NREL) has reported that there are significant reductions in net $\mathrm{CO}_{2}$ emissions from PHEVs [7]. The combination of fluctuating high oil costs, concerns about oil security and availability, and air quality issues related to vehicle emissions are driving interest in PHEVs. The economic incentive for owners to use electricity as fuel is the comparatively low cost of fuel. Considering cost advantages, a study by the Electric Power Research Institute (EPRI) found a significant potential market for PHEVs [8]. However, use of PHEVs will increase the electric load. Moreover, electrification of the transportation sector will need not only the re-structuring of present gasoline stations but also the modification of present electric power infrastructure.

A smart power system is adequate if there is a sufficient power supply to meet customer needs with minimum cost and emission. In the future Cyber-Physical Energy Systems (CPES), GVs should be charged from the grid with renewable sources at offpeak hours and discharged to the grid at peak hours so that cost and emissions are reduced. Researches on PHEVs and EVs are described in [10]-[16]. However, PHEVs and EVs cannot alone solve the emission problem completely, as they need electric power which is one of the main sources of emission. Therefore, success of practical application of PHEVs and EVs greatly depends on the maximum utilization of renewable energy in CPES so that the goal of emission and cost reductions from power systems and transportation sector is achieved. This model consist of intelligent power supply with smart operations to meet customer needs and choices with minimum cost and emissions in this paper. PHEVs and EVs with additional vehicle-to-grid capability and renewable energy sources in CPES can help in this issue. A dynamic optimization approach is needed to optimize the time varying resources in CPES such as RESs and GVs. Thus, a successful bridge can be made between power and transportation infrastructures through GVs.

The authors have reported unit commitment with V2G in [17] where the focus is mainly on cost, emission and cost-emission optimizations. However, in this paper the focus is mainly on smart charging-discharging operations of GVs and maximum utilization of RESs in CPES. Cyber-physical systems refer to the tight coupling of and coordination between computational and physical resources. Thermal units, wind farm, solar farm and GVs are the distributed physical resources considered in the CPES model studied in this paper. Data such as available wind power and solar power, state of charge (SoC) of GVs, load profile, etc. are collected from sensors of the distributed physical resources. On the cyber-side, intelligent computations and decisions are carried out on the dynamic data of the above mentioned physical resources for the maximum utilization of renewable sources using GVs to reduce both cost and emission in CPES.

The objective of a sustainable energy system is not only meeting the present demand but also that of the future
[18]-[21]. Such an energy system takes into consideration the cost and availability of energy resources and their emission in its framework. In this paper, a sustainable integrated electricity and transportation infrastructure is studied and the primary contributions and emphasizes are as follows: 1) illustration of the effectiveness of RESs and GVs for a sustainable CPES; 2) smart and flexible charging-discharging operations of GVs as loads and sources to get benefits from GVs for energy storages in a sustainable CPES; 3) maximum utilization of distributed RESs to reduce emission in a sustainable CPES; and 4) introduction of intelligent load leveling to reduce cost and emission of a system.

The authors make a bridge in the paper between electricity and transportation infrastructures through the sustainable CPES infrastructure. The rest of the paper is organized as follows. In Section II, problem model is formulated for power system and transportation sectors. For proper utilization of resources, and emission and cost minimizations, intelligent optimizations are described in Section III. Input data and results are reported and discussed in Section IV. Finally, the conclusion is given in Section V.

\section{Problem Formulation in CPES}

Distributed RESs, GVs and conventional thermal power plants are physical resources in a typical CPES. In the proposed model: 1) RESs, mainly wind and solar, are used to reduce emission from the power sector; 2) next generation GVs are used to reduce emission from the transportation sector; 3) GVs are smartly used as loads, storages and small portable power plants (S3Ps); 4) parking lots are used as virtual power plants (VPPs); and 5) an onboard system in a GV communicates with utility, real-time pricing center, vehicle owner's preferences, vehicle battery's $\mathrm{SoC}$ and so on. Based on dynamic data from sensors of the large physical system and computations, an optimization method generates intelligent schedules for proper decisions, controls and smart operations in CPES. The system uses GVs to maximize the usage of RESs in order to reduce both electricity cost and emissions from the power and transportation sectors in CPES.

The output of a solar photovoltaic (PV) panel depends on the area of PV panel, solar insolation and the efficiency of the PV panel. Typical efficiency is around $16 \%$. The wind farm model is somewhat more complex due to the mechanical nature of a wind turbine. Generally, the power output of a wind turbine is proportional to the kinetic energy, air density, etc. contained in the wind. In some cases, manufacturer's data sheet is also available. Other parameters of this wind turbine include the cut-in wind speed, cut-out wind speed, and rated wind speed, where typical values are $3.5,25$, and $14 \mathrm{~m} / \mathrm{s}$, respectively.

Wind and solar power may not be sufficient for all the load demand. So, conventional units are also in the system. Wind and solar power is emission free. However in power systems and transportation sectors, the amount of carbon dioxide released is proportion to the amount of carbon in the fuel and the quantity of fuel burnt. Thus, a generation plant or vehicle that burns a carbon-intensive fuel will generate more carbon dioxide at increased levels of operation [22]. Other types of emissions $\left(\mathrm{SO}_{2}\right.$, $\mathrm{NO}_{\mathrm{x}}$, etc.) are also produced from power generation systems 
and transportation sector. For environment friendly power production, emission should be measured.

A linear model is used to calculate emission from vehicles of transportation sector as follows:

$$
\mathcal{E C}_{i}\left(L_{i}, e_{i}\right)=L_{i} \times e_{i}
$$

where $\mathcal{E C}()$ is emission function, $L_{i}$ is the length of travel by vehicle $i$ in mile and $e_{i}$ is emission per mile from vehicle $i$.

However, a nonlinear complex model is available for power system. In this model, emission is expressed as a polynomial function and order depends on desired accuracy. In this paper, a quadratic function is considered for the emission curve as below [23]

$$
\mathcal{E C}_{i}\left(P_{i}(t)\right)=\alpha_{i}+\beta_{i} P_{i}(t)+\gamma_{i} P_{i}^{2}(t)
$$

where $\alpha_{i}, \beta_{i}$, and $\gamma_{i}$ are emission co-efficients of unit $i$.

Fuel cost of a thermal unit is typically expressed as a secondorder function of generated power of the unit

$$
\mathcal{F C}_{i}\left(P_{i}(t)\right)=a_{i}+b_{i} P_{i}(t)+c_{i} P_{i}^{2}(t)
$$

where $a_{i}, b_{i}$, and $c_{i}$ are positive fuel cost co-efficients of unit $i$.

Start-up cost for restarting a decommitted thermal unit, which is related to the temperature of the boiler, is included in the model

$$
\mathcal{S C}_{i}(t)= \begin{cases}h \text {-cost } & \text { if boiler temperature is higher } \\ c \text {-cost } & \text { than a threshold } \\ & \text { if boiler temperature is } \\ & \text { lower than a threshold. }\end{cases}
$$

GVs are considered as loads or S3Ps. In the system considering GVs, power supplied from distributed generations must satisfy the load demand and the system losses, which is defined as

$$
\begin{aligned}
& \sum_{i=1}^{N} P_{i}(t)+P_{\text {wind }}(t)+P_{\text {solar }}(t)+P_{v} N_{V 2 G}(t) \\
& \quad=D(t)+\text { Losses, if GVs are S3Ps } \\
& \sum_{i=1}^{N} P_{i}(t)+P_{\text {wind }}(t)+P_{\text {solar }}(t) \\
& \quad=D(t)+P_{v} N_{V 2 G}(t)+\text { Losses, if GVs are loads. }
\end{aligned}
$$

Only registered gridable vehicles are considered for smart operations. All registered vehicles take part in smart operations during a predefined scheduling period

$$
\sum_{t=1}^{H} N_{V 2 G}(t)=N_{V 2 G}^{\max } .
$$

To maintain system reliability, adequate spinning reserves are required

$$
\begin{gathered}
\sum_{i=1}^{N} P_{i}^{\max }(t)+P_{\text {wind }}(t)+P_{\text {solar }}(t)+P_{v}^{\max } N_{V 2 G}(t) \\
\geq D(t)+R(t), \text { if GVs are S3Ps }
\end{gathered}
$$

$$
\begin{gathered}
\sum_{i=1}^{N} P_{i}^{\max }(t)+P_{\text {wind }}(t)+P_{\text {solar }}(t)+P_{v}^{\max } N_{V 2 G}(t) \\
\geq D(t)+R(t), \text { if GVs are loads. }
\end{gathered}
$$

Each unit has generation range, which is represented as

$$
P_{i}^{\min } \leq P_{i}(t) \leq P_{i}^{\max }
$$

Each vehicle has a desired departure state of charge level $(\Psi)$ and charging/discharging inverter efficiencies are also considered in the model.

In the proposed model, reductions of emissions (2) and generation costs (3)-(4) are considered as objectives of CPES and load balance (5)-(6), registered vehicles (7), reliability reserve (8)-(9), generation limit (10), state of charge, battery efficiency, parking lot limitation, etc. are constraints.

The multi-objective cost and emission reductions are solved as a weighted aggregation form in this paper. Therefore, the objective or fitness function for cost-emission optimization in CPES is -

$$
\min \quad \text { fuel cost, start-up cost, emission\} }
$$

or

$$
\begin{aligned}
& \min _{I_{i}(t), P_{\text {wind }}(t), P_{\text {solar }}(t), N_{V 2 G}(t)} \mathcal{T C} \\
& =\sum_{i=1}^{N} \sum_{t=1}^{H}\left\{\mathcal{W}_{1} \mathcal{F C}_{i}\left(P_{i}(t)\right)+\mathcal{W}_{2} \mathcal{S C}_{i}(t)\left(1-I_{i}(t-1)\right)\right. \\
& \left.\quad+\mathcal{W}_{3} \psi_{i} \mathcal{E C}_{i}\left(P_{i}(t)\right)\right\} I_{i}(t)
\end{aligned}
$$

subject to (5)-(10) constraints.

Decision variables are $I_{i}(t), P_{\text {wind }}(t), P_{\text {solar }}(t)$ and $N_{V 2 G}(t) \cdot \psi_{i}$ is the emission penalty factor of unit $i[17] . \mathcal{W}_{1}$, $\mathcal{W}_{2}$ and $\mathcal{W}_{3}$ are weights of fuel cost, start-up cost and emission respectively.

\section{Cost AND EMISSION OPTIMIZATION IN CPES}

Cost and emissions are non-linear functions of generated output power of thermal units in power system (2)-(3). Conventional thermal units, GVs and RESs are considered in complex multi-dimensional search space with hundreds of constraints in CPES. Moreover, excess load for GVs should be intelligently distributed to off-peak hours to level the demand. An optimization method is required to intelligently handle the system in CPES for maximum utilization of RESs in order to reduce both cost and emission to an optimum level. Particle swarm optimization (PSO) is used to minimize cost and emission in this study because of its merits: i) PSO can optimize binary, integer and real decision variables; ii) it can handle constraints; iii) it is easy to implement, fast and robust; and (iv) it has balance between local and global search abilities. PSO is a bio-inspired algorithm based on the behavior of flock of birds and school of fish, and has similarities to other population based evolutionary algorithms [24]. Each potential solution, called a particle, flies in a multi-dimensional search space with a velocity, which is 
dynamically adjusted according to the flying experience of its own and other particles.

PSO is an iterative method where velocity and position of each particle are calculated as follows:

$v_{r j}(k+1)=\left[v_{r j}(k)+c_{1} \operatorname{rand}_{1}\left(\operatorname{pbest}_{r j}(k)-x_{r j}(k)\right)\right.$

$\left.+c_{2} \operatorname{rand}_{2}\left(\operatorname{gbest}_{j}(k)-x_{r j}(k)\right)\right]\left[1+\frac{- \text { Range }}{\text { MaxIte }}(\right.$ Ite-1) $)$.

Binary PSO for conventional units:

$I_{r j}(k+1)=x_{r j}(k+1)= \begin{cases}1, & \text { if } U(1)<\frac{1}{1+\exp \left(-v_{r j}(k+1)\right)} \\ 0, & \text { otherwise. }\end{cases}$

Integer PSO for GVs:

$N_{V 2 G_{r j}}(k+1)=x_{r j}(k+1)=\operatorname{round}\left(x_{r j}(k)+v_{r j}(k+1)\right)$.

Real PSO for renewable sources:

$$
\begin{aligned}
& P_{\text {solar }_{r j}}=x_{r j}(k+1)=x_{r j}(k)+v_{r j}(k+1) \\
& P_{\text {wind }_{r j}}=x_{r j}(k+1)=x_{r j}(k)+v_{r j}(k+1) .
\end{aligned}
$$

Here, a particle's best position pbest, global best position gbest, velocity $v$, position $x$, accelerating parameters $c_{1}$ and $c_{2}$, particle no. $r$, problem dimension $j$ (considering all resources and scheduling period), and iteration index $k$ are standard terms of PSO [24]. $I_{r j}$ and $x_{r j}$ are matrices of sizes $H \times N$ and $H \times(N+3)$ respectively. However, $N_{V 2 G_{r j}}$ is a column vector of $H \times 1$ integers for $\mathrm{GVs}$ that reduces dimension; $P_{\text {solar }}$ is a column vector of size $H \times 1$ for solar power; $P_{\text {wind }}$ is a column vector of size $H \times 1$ for wind power; and $x=\left[\begin{array}{ll}I & N_{V 2 G} \\ P_{\text {solar }} & P_{\text {wind }}\end{array}\right]$. Conventional units, GVs and RESs (wind and solar) are represented by different values of dimension $j$ in $x$. Ite, MaxIte and $U(1)$ are current iteration, maximum number of iterations, and a uniform number between 0 and 1 respectively. In the above velocity (12), the first term indicates the current velocity of the particle (inertia term); the second term presents the cognitive term of the particle where the particle changes its velocity based on its own private thinking and memory; and the third term is the social part where the particle changes its velocity based on knowledge derived from the interaction with other particles in the swarm. The second part of (12) provides a balance between local and global search abilities. Binary and integer PSOs are used in order to reduce the search space dimension in this optimization problem. Conventional units and GVs are represented by binary and integer numbers respectively. Binary PSO is used to determine the optimal on/off states of conventional units (13). Integer PSO is used to determine the optimal number of GVs in the constrained system (14). Real PSO is used to determine the optimal levels of solar and wind power (15)-(16). A flowchart for minimization of cost and emission using GVs and RESs in CPES is given in Fig. 1. Lambda iteration is used for dispatch of the energy resources.

\section{RESULTS}

An independent system operator (ISO) of 10-unit system is considered for simulation with $50000 \mathrm{GVs}$. Load demand and unit characteristics of the 10-unit system are collected from [25].

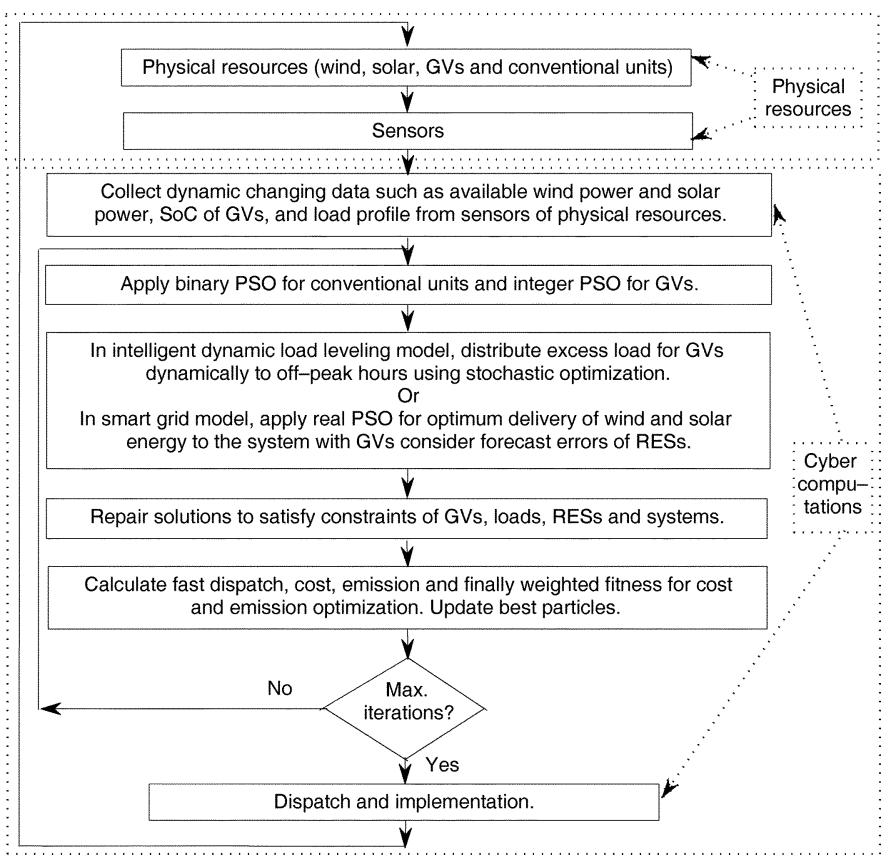

Fig. 1. Flowchart for the maximum utilization of renewable energy sources in CPES with GVs.

TABLE I

GENERATOR EMISSION CO-EFFICIENTS

\begin{tabular}{|c|c|c|c|}
\hline Unit & $\begin{array}{c}\alpha_{i} \\
\text { (ton/h) }\end{array}$ & $\begin{array}{c}\beta_{i} \\
\text { (ton/MWh) }\end{array}$ & $\begin{array}{c}\gamma_{i} \\
\text { (ton/MW } / \mathrm{MW}^{2} \mathrm{~h}\end{array}$ \\
\hline $\mathrm{U}-1$ & 10.33908 & -0.24444 & 0.00312 \\
$\mathrm{U}-2$ & 10.33908 & -0.24444 & 0.00312 \\
$\mathrm{U}-3$ & 30.03910 & -0.40695 & 0.00509 \\
$\mathrm{U}-4$ & 30.03910 & -0.40695 & 0.00509 \\
$\mathrm{U}-5$ & 32.00006 & -0.38132 & 0.00344 \\
$\mathrm{U}-6$ & 32.00006 & -0.38132 & 0.00344 \\
$\mathrm{U}-7$ & 33.00056 & -0.39023 & 0.00465 \\
$\mathrm{U}-8$ & 33.00056 & -0.39023 & 0.00465 \\
$\mathrm{U}-9$ & 35.00056 & -0.39524 & 0.00465 \\
$\mathrm{U}-10$ & 36.00012 & -0.39864 & 0.00470 \\
\hline
\end{tabular}

TABLE II

PlANT SizE AND MAXIMUM CAPACITY (1662 MW) OF 10-UNIT SySTEM

\begin{tabular}{l|c|c|c|c|c}
\hline & Unit 1 & Unit 2 & Unit 3 & Unit 4 & Unit 5 \\
\hline$P_{i}^{\text {max }}(\mathrm{MW})$ & 455 & 455 & 130 & 130 & 162 \\
\hline$P_{i}^{\text {min }}(\mathrm{MW})$ & 150 & 150 & 20 & 20 & 25 \\
\hline \hline & Unit 6 & Unit 7 & Unit 8 & Unit 9 & Unit 10 \\
\hline$P_{i}^{\text {max }}(\mathrm{MW})$ & 80 & 85 & 55 & 55 & 55 \\
\hline$P_{i}^{\text {min }}(\mathrm{MW})$ & 20 & 25 & 10 & 10 & 10 \\
\hline
\end{tabular}

Emissions from coal-fired, petroleum and natural gas power plants are quite different. It is assumed that conventional thermal units are coal-fired because of low operational cost and their estimated emission co-efficients are given in Table I. Plant data is given in Table II. Three models are investigated to show the effect of GVs in power systems and transportation sector.

- Case 1 - random model: GVs are charged/discharged randomly;

- Case 2 - intelligent dynamic load leveling model: GVs are charged from conventional generation using load leveling optimization.

- Case 3 - smart grid model: GVs are charged from the grid with renewable sources at off-peak hours and discharged to the grid at peak hours. 


\section{Parameter values are -}

estimated total number of vehicles in the system $=50,000$; maximum battery capacity $=25 \mathrm{kWh}$; minimum battery capacity $=10 \mathrm{kWh}$;

average battery capacity, $P_{v}=15 \mathrm{kWh}$; charging-discharging frequency $=1$ per day; scheduling period $=24 \mathrm{~h}$; departure state of charge, $\Psi=50 \%$; efficiency, $\xi=85 \%$ (in smart grid model); weights $\mathcal{W}_{1}=\mathcal{W}_{2}=\mathcal{W}_{3}=1$ (equally important); for PSO, swarm size $=30$, iteration $=1,000$ and accelerating parameters $c_{1}=1.5, c_{2}=2.5$.

\section{A. Random Model}

If $50,000 \mathrm{GVs}$ are connected to the grid randomly, roughly an excess of $(50,000 * 15 \mathrm{kWh}=) 750$-MWh power will be needed for the small system of a city. No optimization method is applied, as the system is fully random. In that system, peak load will be approximately $50 \%$ more in the worst case (if charging time is $1 \mathrm{~h}$ ) and thus the system is practically not feasible.

\section{B. Intelligent Dynamic Load Leveling Model}

As the random model is not feasible, the next possible solution is load leveling. For practical applications, the number of GVs in an electric power network can be estimated analytically based on the number of electricity clients (customers) in that network. An estimate of gridable vehicles from residential electricity clients may be computed as follows:

$$
\begin{aligned}
N_{G V} & =N V_{U C-V 2 G} V_{R E C} N_{R E C} \\
& =\frac{N V_{U C-V 2 G} V_{R E C} X_{R L} L_{\min }}{A V_{H L D}} \\
A V_{H L D} & =\frac{A V_{M E C}}{(30 * 24)}
\end{aligned}
$$

where

$$
\begin{aligned}
& N_{G V} \quad \text { number of GVs; } \\
& N V_{U C-V 2 G} \quad \% \text { of the number of registered GVs for } \\
& \text { participation in smart operations; } \\
& V_{R E C} \quad \text { average number of gridable vehicles per } \\
& \text { residential electricity client; } \\
& N_{R E C} \quad \text { number of residential electricity clients; } \\
& X_{R L} \quad \text { percentage of residential loads in the power } \\
& \text { network; } \\
& L_{\min } \quad \text { minimum load in the power network at } \\
& \text { given time (MW); }
\end{aligned}
$$

For example: the minimum load, $L_{\min }$, in the 10-unit benchmark system considered in this research is $700 \mathrm{MW}$ [25]. It can be taken that the average monthly electricity consumption,
$A V_{M E C}$, of a domestic home is about $1500 \mathrm{kWh}$ [26]. Thus, average hourly electricity load of a residential client, $A V_{H L D}$, is $2.0833 \mathrm{~kW}$. If we assume that $X_{R L}=30 \%$, the total number of clients in the region $N_{R E C}$, is 100801.6 and it can be rounded to 100000 for simplicity. It is reasonable to assume that in the future, $V_{R E C}=1$, i.e., on average there will be one gridable vehicle per residential electricity client, and $N V_{U C-V 2 G}=50 \%$, i.e., $50 \%$ register to participate in the process. Thus, $N_{G V}$ from (17) is about 50000 and this is a reasonable number of vehicles to be considered on the 10-unit benchmark system for our simulation studies.

Excess energy for the GVs of the system can be estimated as follows:

$$
E_{G V}=\left(\frac{L_{G V}}{M_{G V}}\right) N_{V 2 G}^{\max }
$$

where

$E_{G V} \quad$ excess electric energy for GVs per day;

$L_{G V} \quad$ average length of travel (in mile) per day;

$M_{G V} \quad$ mileage of a $\mathrm{GV}$ per $\mathrm{kWh}$;

$N_{V 2 G}^{\max } \quad$ number of GVs.

Average length of travel, $L_{G V}$ is $(12,000 \mathrm{mi} / 365=)$ $32.88 \mathrm{mi} /$ day, as an average distance driven with a vehicle is about $12,000 \mathrm{mi} /$ year [26]. Typical mileage of a GV, $M_{G V}$ is $4 \mathrm{mi} / \mathrm{kWh}$. Therefore, a GV needs about $(32.88 / 4=) 8.22 \mathrm{kWh} /$ day. From (19), excess energy $E_{G V}$ is $(50,000 * 8.22 \mathrm{kWh}=) 411 \mathrm{MWh}$ in a small system of 50000 GVs each day.

If the GVs are not regulated, in the worst case peak load will be increased by $411 / \delta \mathrm{MW}$ which is very costly for the system if charging time, $\delta$ is short. However, intelligent scheduling of GVs can soften the problem by leveling the excess load demand intelligently. Load curve of the standard 10-unit system has both peaks and valleys (see Fig. 2). According to the load curve, demand is relatively low during hours from 1st to 9th and from 14th to 24th (total $20 \mathrm{~h}$ ). GVs can be charged from the grid during the off-peak load to level the demand. In the proposed method, extra $411 \mathrm{MWh}$ load for 50000 vehicles is intelligently distributed in the dynamic optimization model among off-peak hours without increasing the peak load so that cost and emissions are minimized (see dashed-dotted line of Fig. 2). The proposed intelligent dynamic load leveling is better than typical static load leveling where excess load is equally distributed to off-peak hours, because it may not be the optimum load leveling for cost and emission reductions.

In transportation, it is already mentioned that the average distance driven with a vehicle is about $12000 \mathrm{mi}$ per year and average emission from a light weight vehicle is $1.2 \mathrm{lb} / \mathrm{mi}$. So, emission from a vehicle over a year is $(12,000 * 1.2=) 14400 \mathrm{lbs}$ using (1) and total emission from 50000 mechanical vehicles is $720000000 \mathrm{lbs}$ (326678.76 tons) in transportation sector.

A nonlinear model is applied for emission from power plants (2). First, emission is calculated for the 10-unit system with standard input data of power plants, emission co-efficients and load demand without considering GVs. PSO is used to calculate the schedule, power dispatch and corresponding emission. 
TABLE III

EMissions, COST AND DisPatch OF 10-Unit SYSTEM (Without GVS AND RENEWABLE SourCES)

\begin{tabular}{|c|c|c|c|c|c|c|c|c|c|c|c|c|}
\hline $\begin{array}{c}\text { Time } \\
(\mathrm{H})\end{array}$ & $\begin{array}{c}\mathrm{U}-1 \\
(\mathrm{MW})\end{array}$ & $\begin{array}{c}\mathrm{U}-2 \\
(\mathrm{MW})\end{array}$ & $\begin{array}{c}\mathrm{U}-3 \\
\text { (MW) }\end{array}$ & $\begin{array}{c}\mathrm{U}-4 \\
\text { (MW) }\end{array}$ & $\begin{array}{c}\mathrm{U}-5 \\
\text { (MW) }\end{array}$ & $\begin{array}{c}\mathrm{U}-6 \\
\text { (MW) }\end{array}$ & $\begin{array}{c}\mathrm{U}-7 \\
(\mathrm{MW})\end{array}$ & $\begin{array}{c}\mathrm{U}-8 \\
(\mathrm{MW})\end{array}$ & $\begin{array}{c}\text { U-9 } \\
(\mathrm{MW})\end{array}$ & $\begin{array}{c}\mathrm{U}-10 \\
\text { (MW) }\end{array}$ & $\begin{array}{l}\text { Emission } \\
\text { (ton) }\end{array}$ & $\begin{array}{c}\text { Demand } \\
(\mathrm{MW})\end{array}$ \\
\hline 1 & 455.0 & 244.9 & 0.0 & 0.0 & 0.0 & 0.0 & 0.0 & 0.0 & 0.0 & 0.0 & 682.699 & 700.0 \\
\hline 2 & 455.0 & 295.0 & 0.0 & 0.0 & 0.0 & 0.0 & 0.0 & 0.0 & 0.0 & 0.0 & 754.716 & 750.0 \\
\hline 3 & 455.0 & 265.0 & 130.0 & 0.0 & 0.0 & 0.0 & 0.0 & 0.0 & 0.0 & 0.0 & 772.805 & 850.0 \\
\hline 4 & 455.0 & 364.9 & 130.0 & 0.0 & 0.0 & 0.0 & 0.0 & 0.0 & 0.0 & 0.0 & 944.857 & 950.0 \\
\hline 5 & 455.0 & 285.0 & 130.0 & 130.0 & 0.0 & 0.0 & 0.0 & 0.0 & 0.0 & 0.0 & 865.388 & 1000.0 \\
\hline 6 & 455.0 & 385.0 & 130.0 & 130.0 & 0.0 & 0.0 & 0.0 & 0.0 & 0.0 & 0.0 & 1049.963 & 1100.0 \\
\hline 7 & 455.0 & 410.0 & 130.0 & 130.0 & 25.0 & 0.0 & 0.0 & 0.0 & 0.0 & 0.0 & 1130.456 & 1150.0 \\
\hline 8 & 455.0 & 455.0 & 130.0 & 130.0 & 25.0 & 0.0 & 0.0 & 0.0 & 0.0 & 0.0 & 1241.004 & 1200.0 \\
\hline 9 & 455.0 & 455.0 & 130.0 & 130.0 & 104.9 & 0.0 & 25.0 & 0.0 & 0.0 & 0.0 & 1272.402 & 1300.0 \\
\hline 10 & 455.0 & 455.0 & 130.0 & 130.0 & 162.0 & 0.0 & 25.0 & 10.0 & 0.0 & 0.0 & 1332.607 & 1400.0 \\
\hline 11 & 455.0 & 455.0 & 130.0 & 130.0 & 162.0 & 0.0 & 25.0 & 55.0 & 0.0 & 10.0 & 1361.131 & 1450.0 \\
\hline 12 & 455.0 & 455.0 & 130.0 & 130.0 & 162.0 & 0.0 & 47.9 & 55.0 & 55.0 & 10.0 & 1387.289 & 1500.0 \\
\hline 13 & 455.0 & 455.0 & 130.0 & 130.0 & 162.0 & 0.0 & 25.0 & 10.0 & 0.0 & 0.0 & 1332.607 & 1400.0 \\
\hline 14 & 455.0 & 455.0 & 130.0 & 130.0 & 104.9 & 0.0 & 25.0 & 0.0 & 0.0 & 0.0 & 1272.402 & 1300.0 \\
\hline 15 & 455.0 & 455.0 & 130.0 & 130.0 & 25.0 & 0.0 & 0.0 & 0.0 & 0.0 & 0.0 & 1241.004 & 1200.0 \\
\hline 16 & 455.0 & 309.9 & 130.0 & 130.0 & 25.0 & 0.0 & 0.0 & 0.0 & 0.0 & 0.0 & 930.244 & 1050.0 \\
\hline 17 & 455.0 & 260.0 & 130.0 & 130.0 & 25.0 & 0.0 & 0.0 & 0.0 & 0.0 & 0.0 & 853.614 & 1000.00 \\
\hline 18 & 455.0 & 360.0 & 130.0 & 130.0 & 25.0 & 0.0 & 0.0 & 0.0 & 0.0 & 0.0 & 1022.576 & 1100.00 \\
\hline 19 & 455.0 & 455.0 & 130.0 & 130.0 & 25.0 & 0.0 & 0.0 & 0.0 & 0.0 & 0.0 & 1241.004 & 1200.00 \\
\hline 20 & 455.0 & 455.0 & 130.0 & 130.0 & 162.0 & 0.0 & 0.0 & 10.0 & 10.0 & 10.0 & 1370.453 & 1400.00 \\
\hline 21 & 455.0 & 455.0 & 130.0 & 130.0 & 119.9 & 0.0 & 0.0 & 0.0 & 10.0 & 0.0 & 1283.647 & 1300.00 \\
\hline 22 & 455.0 & 385.0 & 130.0 & 130.0 & 0.0 & 0.0 & 0.0 & 0.0 & 0.0 & 0.0 & 1049.963 & 1100.00 \\
\hline 23 & 455.0 & 315.0 & 0.0 & 130.0 & 0.0 & 0.0 & 0.0 & 0.0 & 0.0 & 0.0 & 851.033 & 900.00 \\
\hline 24 & 455.0 & 345.0 & 0.0 & 0.0 & 0.0 & 0.0 & 0.0 & 0.0 & 0.0 & 0.0 & 842.310 & 800.00 \\
\hline
\end{tabular}

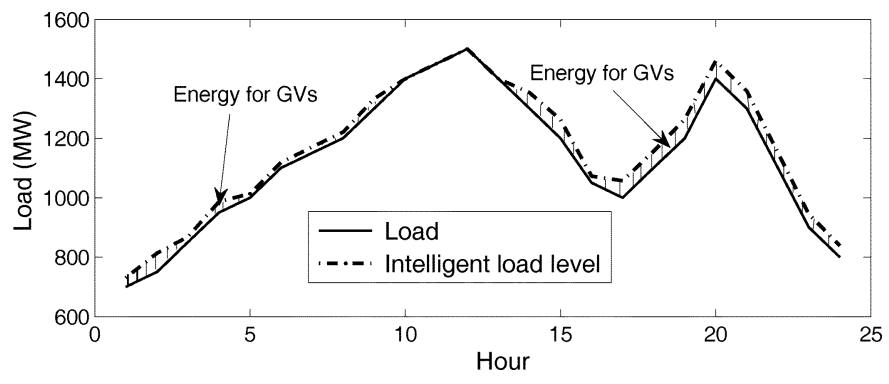

Fig. 2. Intelligent load leveling for GVs using optimization to reduce both cost and emission.

Results are shown in Table III. Then emission is calculated considering load demand including $50000 \mathrm{GVs}$ and leveling the extra load intelligently in the optimization model (Fig. 2). These results are shown in Table IV. From Tables III and IV, excess emission is 491.311 tons ( $26,577.483$ tons $-26,086.172$ tons) from power plants to supply energy to the $50000 \mathrm{GVs}$ during $24 \mathrm{~h}$. So excess emission is $(491.311 * 365=) 179328.515$ tons per year (on the other hand 326678.766 tons from transportation sector). However, system efficiency and network losses are not considered in the model. So considering overall system efficiency and losses, emission will not be significantly reduced using intelligent load leveling only, as emission will be shifted from transportation sector to power system. Modern technologies for mileage-efficient GVs and modern emission absorption techniques for power plants can reduce emission in this model. Usually the overall efficiency of GVs (23.1\%) is higher than that of conventional vehicles (12.6\%) considering fuel energy that drives the wheels. On the other hand, emissions may be increased for system efficiencies and network losses of power systems. The same as emission, operation cost will not be significantly decreased in the load leveling model, as operation cost will be shifted from the transportation sector to power sector.
However, transportation fuel price is more volatile and the proposed model reduces dependency on it, which is very important in the present world.

For the load leveling model, scheduling and control of GVs are very important, as today's vehicle owners with increase in fuel cost and emission taxations over time will start having more of electric and hybrid vehicles. It will be possible to control V2G/G2V nicely based on policies, incentives and rebates put in place by the government, utilities and gridable manufacturers. Utility may provide incentives/rebates on vehicle batteries in return for $\mathrm{V} 2 \mathrm{G}$ participation. Under such conditions, vehicle use culture/habit will most likely change and GV owners will allow their vehicles to charge/discharge in recommended hours by the utilities. GVs embedded with advanced features for V2G/G2V operations will be attractive and the easiness will be additional factor for the culture change. Examples of these advanced features include the use as an automatic intelligent agent to: 1) make charging decisions based on real-time pricing and 2) communicate with a utility agent on the GV's availability for V2G operations and state of battery charge needed at the departure time. It has been mentioned earlier that each day a vehicle covers an average estimated distance of $32.88 \mathrm{mi}$ and thus takes roughly less than one hour of travel time. Therefore, it can be said that a vehicle is parked most of the time of a day, either in a parking lot or in a home garage. Vehicles can be charged/discharged during the time of a day when they are parked using automatic intelligent agents. The authors have described the practicality and controllability of GVs in [17].

\section{Smart Grid Model}

It is necessary to integrate RESs (wind and solar) in the sustainable CPES to reduce cost and emission. For a small city with $50000 \mathrm{GVs}$, at least $(50,000 * 15 \mathrm{kWh}=) 750$-MWh new wind and solar energy is needed to get the full benefit of GVs for 
TABLE IV

EMISSIONS, Cost AND DisPatch OF 10-UNit SySTEM With 50000 GVS IN INTELLIGENT LOAD LEVELING MODEL

\begin{tabular}{|c|c|c|c|c|c|c|c|c|c|c|c|c|c|c|}
\hline $\begin{array}{l}\text { Time } \\
(\mathrm{H})\end{array}$ & $\begin{array}{l}\text { U-1 } \\
\text { (MW) }\end{array}$ & $\begin{array}{c}\text { U-2 } \\
\text { (MW) }\end{array}$ & $\begin{array}{l}\text { U-3 } \\
\text { (MW) }\end{array}$ & $\begin{array}{l}\text { U-4 } \\
\text { (MW) }\end{array}$ & $\begin{array}{c}\text { U-5 } \\
\text { (MW) }\end{array}$ & $\begin{array}{c}\text { U-6 } \\
\text { (MW) }\end{array}$ & $\begin{array}{c}\mathrm{U}-7 \\
(\mathrm{MW})\end{array}$ & $\begin{array}{l}\text { U-8 } \\
\text { (MW) }\end{array}$ & $\begin{array}{c}\text { U-9 } \\
\text { (MW) }\end{array}$ & $\begin{array}{c}\text { U-10 } \\
(\mathrm{MW})\end{array}$ & $\begin{array}{l}\text { Emission } \\
\text { (ton) }\end{array}$ & $\begin{array}{c}\text { Capacity } \\
\text { (MW) }\end{array}$ & $\begin{array}{l}\text { Demand }{ }^{*} \\
\text { (MW) }\end{array}$ & $\begin{array}{l}\text { Reserve } \\
\text { (MW) }\end{array}$ \\
\hline 1 & 455.0 & 260.3 & 0.0 & 0.0 & 0.0 & 0.0 & 0.0 & 0.0 & 0.0 & 0.0 & 703.193 & 910.00 & 715.39 & 194.61 \\
\hline 2 & 455.0 & 326.6 & 0.0 & 0.0 & 0.0 & 0.0 & 0.0 & 0.0 & 0.0 & 0.0 & 808.302 & 910.00 & 781.63 & 128.37 \\
\hline 3 & 455.0 & 404.1 & 0.0 & 0.0 & 0.0 & 0.0 & 0.0 & 0.0 & 0.0 & 0.0 & 966.066 & 910.00 & 859.15 & 50.85 \\
\hline 4 & 455.0 & 253.2 & 130.0 & 130.0 & 0.0 & 0.0 & 0.0 & 0.0 & 0.0 & 0.0 & 819.824 & 1170.00 & 968.26 & 201.74 \\
\hline 5 & 455.0 & 291.7 & 130.0 & 130.0 & 0.0 & 0.0 & 0.0 & 0.0 & 0.0 & 0.0 & 875.887 & 1170.00 & 1006.78 & 163.22 \\
\hline 6 & 455.0 & 394.1 & 130.0 & 130.0 & 0.0 & 0.0 & 0.0 & 0.0 & 0.0 & 0.0 & 1069.875 & 1170.00 & 1109.11 & 60.89 \\
\hline 7 & 455.0 & 435.1 & 130.0 & 130.0 & 0.0 & 0,0 & 0.0 & 0.0 & 10.0 & 0.0 & 1197.600 & 1225.00 & 1160.10 & 64.90 \\
\hline 8 & 455.0 & 455.0 & 130.0 & 130.0 & 37.5 & 0.0 & 0.0 & 0.0 & 0.0 & 0.0 & 1238.923 & 1332.00 & 1210.37 & 121.63 \\
\hline 9 & 455.0 & 455.0 & 130.0 & 130.0 & 126.2 & 20.0 & 0.0 & 0.0 & 0.0 & 0.0 & 1280.814 & 1412.00 & 1316.30 & 95.70 \\
\hline 10 & 455.0 & 455.0 & 130.0 & 130.0 & 162.0 & 42.4 & 25.0 & 0.0 & 0.0 & 0.0 & 1325.064 & 1497.01 & 1400.00 & 97.01 \\
\hline 11 & 455.0 & 455.0 & 130.0 & 130.0 & 162.0 & 80.0 & 25.0 & 10.0 & 0.0 & 0.0 & 1356.117 & 1552.00 & 1450.00 & 102.00 \\
\hline 12 & 455.0 & 455.0 & 130.0 & 130.0 & 162.0 & 80.0 & 25.0 & 52.1 & 10.0 & 0.0 & 1383.362 & 1607.00 & 1500.00 & 107.00 \\
\hline 13 & 455.0 & 455.0 & 130.0 & 130.0 & 162.0 & 42.4 & 25.0 & 0.0 & 0.0 & 0.0 & 1325.064 & 1497.00 & 1400.00 & 97.00 \\
\hline 14 & 455.0 & 455.0 & 130.0 & 130.0 & 136.7 & 20.0 & 0.0 & 0.0 & 0.0 & 0.0 & 1286.296 & 1412.00 & 1326.77 & 85.23 \\
\hline 15 & 455.0 & 455.0 & 130.0 & 130.0 & 61.1 & 0.0 & 0.0 & 0.0 & 0.0 & 0.0 & 1237.929 & 1332.00 & 1231.13 & 100.87 \\
\hline 16 & 455.0 & 321.1 & 130.0 & 130.0 & 25.0 & 0.0 & 0.0 & 0.0 & 0.0 & 0.0 & 949.456 & 1332.00 & 1061.14 & 270.86 \\
\hline 17 & 455.0 & 288.5 & 130.0 & 130.0 & 25.0 & 0.0 & 0.0 & 0.0 & 0.0 & 0.0 & 895.445 & 1332.00 & 1028.53 & 303.47 \\
\hline 18 & 455.0 & 388.1 & 130.0 & 130.0 & 25.0 & 0.0 & 0.0 & 0.0 & 0.0 & 0.0 & 1081.451 & 1332.00 & 1128.18 & 203.82 \\
\hline 19 & 455.0 & 455.0 & 130.0 & 130.0 & 61.6 & 0.0 & 0.0 & 0.0 & 0.0 & 0.0 & 1237.951 & 1332.00 & 1231.66 & 100.34 \\
\hline 20 & 455.0 & 455.0 & 130.0 & 130.0 & 162.0 & 0.0 & 0.0 & 55.0 & 24.7 & 10.0 & 1363.050 & 1497.00 & 1430.11 & 66.89 \\
\hline 21 & 455.0 & 455.0 & 130.0 & 130.0 & 149.3 & 0.0 & 0.0 & 10.0 & 0.0 & 0.0 & 1297.726 & 1387.00 & 1329.41 & 57.59 \\
\hline 22 & 455.0 & 410.6 & 130.0 & 130.0 & 0.0 & 0.0 & 0.0 & 0.0 & 0.0 & 0.0 & 1107.338 & 1170.00 & 1125.67 & 44.33 \\
\hline 23 & 455.0 & 337.2 & 130.0 & 0.0 & 0.0 & 0.0 & 0.0 & 0.0 & 0.0 & 0.0 & 890.830 & 1040.00 & 922.22 & 117.78 \\
\hline 24 & 455.0 & 364.1 & 0.0 & 0.0 & 0.0 & 0.0 & 0.0 & 0.0 & 0.0 & 0.0 & 879.920 & 909.99 & 819.10 & 90.89 \\
\hline
\end{tabular}

reducing cost and emission. If the energy ratio from wind and solar is taken as 2:1, 500 MWh and $250 \mathrm{MWh}$ of wind and solar energy respectively are available. This assumption is based on there being sufficient wind speed and solar insolation profiles for the location studied. For a given location, a realistic wind farm and solar farm size can be estimated using an optimization algorithm based on wind speed and solar insolation data over a period of time. In this study, solar insolation data is collected from NREL's Solar Radiation Research Laboratory (SRRL) in Golden, CO [27] for the solar farm model. Wind speed data is collected from the National Wind Technology Center (NWTC) in Boulder, $\mathrm{CO}$ [28] for the wind farm model. The wind farm and solar farm sizes are estimated to be 25.5 and $40 \mathrm{MW}(16 \%$ photovoltaic panel efficiency), respectively, and a typical day in the month of January forecasts of wind and solar energy are given in Table V.

In the smart grid model, GVs can be used as loads, S3Ps and storages. GVs can be utilized for harnessing renewable energy, storage, transportation, and providing power for both residential and commercial customers. The amount of cost and emission reductions mainly depends on maximum utilization of renewable energy through GVs, where GVs can discharge as well as charge. GVs are charged/discharged intelligently so that both cost and emission are minimum; however, load demand and constraints are fulfilled. Standard 10-unit system with $50000 \mathrm{GVs}$ is studied for minimizing cost and emission, and PSO is used for optimization. Results are shown in Table VI.

In Table VI, emission is 24852.583 tons and cost is $\$ 553776.56$ when 50,000 GVs and RESs are considered in the 10-unit system during $24 \mathrm{~h}$ in the smart grid. On the other hand, emission is 26086.172 tons when GVs and RESs are not considered in the same system (Table III). Thus, smart grid with RESs and GVs reduces $(26,086.172$ tons $-24,852.583$ tons $=)$ 1233.589 tons of emission per day or 450259.985 tons per year from power sector of 10 -unit small system. Besides 50,000 GVs will replace 50000 conventional vehicles and it is already calculated that emission is 326678.766 tons from the 50,000 vehicles. So smart grid will reduce total 776938.751 tons
TABLE V

FORECASTS OF WIND AND SOLAR ENERGY (A TYPICAL DAY IN THE MONTH OF JANUARY)

\begin{tabular}{|c|c|c|}
\hline Hour & Wind (MW) & Solar (MW) \\
\hline 1 & 10.54 & 0 \\
2 & 22.27 & 0 \\
3 & 25.5 & 0 \\
4 & 25.5 & 0 \\
5 & 25.5 & 0 \\
6 & 25.5 & 0 \\
7 & 25.5 & 0.09 \\
8 & 25.5 & 17.46 \\
9 & 25.5 & 31.45 \\
10 & 25.5 & 36.01 \\
11 & 25.5 & 38.06 \\
12 & 25.5 & 35.93 \\
13 & 25.5 & 36.78 \\
14 & 24.82 & 31.59 \\
15 & 20.74 & 9.7 \\
16 & 14.62 & 12.92 \\
17 & 25.5 & 0 \\
18 & 19.04 & 0 \\
19 & 25.5 & 0 \\
20 & 18.02 & 0 \\
21 & 25.5 & 0 \\
22 & 21.42 & 0 \\
23 & 0 & 0 \\
24 & 2.55 & 0 \\
\hline \multicolumn{3}{|c|}{ Solar farm size $=40 \mathrm{MW}$} \\
Wind farm size $=25.5 \mathrm{MW}$ \\
\hline \multicolumn{2}{|c}{}
\end{tabular}

(450 259.985 + 326678.766$)$ emission from power systems and transportation sector.

Fuel cost is highly volatile. The benchmark fuel cost co-efficients that are used in this simulation, are old. Thus, present cost co-efficients are much higher as current fuel cost is scaled up a lot since last decade. According to the results, smart grid with RESs and GVs saves at least $(\$ 557,744.29-\$ 553,776.56=)$ $\$ 3967.73$ per day in the 10 -unit small system. It will also save running cost from the transportation sector. It is assumed that mileage of a light weight vehicle is $20 \mathrm{mi} / \mathrm{gallon}$ and present gasoline price is $\$ 2.6 /$ gallon. So, transportation fuel cost will be reduced by $(50,000 *(32.88 \mathrm{mile} / 20$ mile $) * \$ 2.6=) \$ 213720$ 
TABLE VI

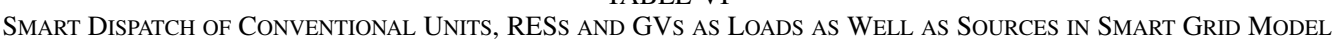

\begin{tabular}{|c|c|c|c|c|c|c|c|c|c|c|c|c|c|c|c|c|c|}
\hline $\begin{array}{c}\text { Time } \\
(\mathrm{H})\end{array}$ & $\begin{array}{c}\text { U-1 } \\
\text { (MW) }\end{array}$ & $\begin{array}{l}\text { U-2 } \\
\text { (MW) }\end{array}$ & $\begin{array}{l}\text { U-3 } \\
(\mathrm{MW})\end{array}$ & $\begin{array}{c}\text { U-4 } \\
(\mathrm{MW})\end{array}$ & $\begin{array}{l}\text { U-5 } \\
\text { (MW) }\end{array}$ & $\begin{array}{l}\text { U-6 } \\
(\mathrm{MW})\end{array}$ & $\begin{array}{c}\text { U-7 } \\
\text { (MW) }\end{array}$ & $\begin{array}{l}\text { U-8 } \\
\text { (MW) }\end{array}$ & $\begin{array}{l}\text { U-9 } \\
\text { (MW) }\end{array}$ & $\begin{array}{l}\text { U-10 } \\
\text { (MW) }\end{array}$ & $\begin{array}{c}\mathrm{V} 2 \mathrm{G} / \mathrm{G} 2 \mathrm{~V} \\
\text { (MW) }\end{array}$ & $\begin{array}{l}\text { Solar }^{1} \\
\text { (MW) }\end{array}$ & $\begin{array}{l}\text { Wind }^{1} \\
(\mathrm{MW})\end{array}$ & $\begin{array}{c}\text { Emission } \\
\text { (ton) }\end{array}$ & $\begin{array}{c}\text { Capacity } \\
\text { (MW) }\end{array}$ & $\begin{array}{c}\text { Demand }^{2} \\
\text { (MW) }\end{array}$ & $\begin{array}{c}\begin{array}{c}\text { Reserve } \\
(\mathrm{MW})\end{array} \\
\end{array}$ \\
\hline 1 & 455.0 & 154,2 & 0.0 & 130.0 & 0.0 & 0.0 & 0.0 & 0.0 & 0.0 & 0.0 & -50.01 & 0.00 & 10.73 & 655.056 & 1090.0 & 700.0 & 390.0 \\
\hline 2 & 455.0 & 156.8 & 0.0 & 130.0 & 0.0 & 0.0 & 0.0 & 0.0 & 0.0 & 0.0 & -14.32 & 0.00 & 22.45 & 656.939 & 1054.3 & 750.0 & 304.3 \\
\hline 3 & 455.0 & 150.0 & 114.1 & 130.0 & 0.0 & 0.0 & 0.0 & 0.0 & 0.0 & 0.0 & -24.09 & 0.00 & 25.05 & 701.944 & 1194.1 & 850.0 & 344.1 \\
\hline 4 & 455.0 & 232.9 & 130.0 & 130.0 & 0.0 & 0.0 & 0.0 & 0.0 & 0.0 & 0.0 & -23.07 & 0.00 & 25.10 & 794.016 & 1193.1 & 950.0 & 243.1 \\
\hline 5 & 455.0 & 255.7 & 130.0 & 130.0 & 25.0 & 0.0 & 0.0 & 0.0 & 0.0 & 0.0 & -21.14 & 0.00 & 25.35 & 847.858 & 1353.1 & 1000.0 & 353.1 \\
\hline 6 & 455.0 & 352.7 & 130.0 & 130.0 & 25.0 & 0.0 & 0.0 & 0.0 & 0.0 & 0.0 & -18.28 & 0.00 & 25.50 & 1008.261 & 1350.3 & 1100.0 & 250.3 \\
\hline 7 & 455.0 & 398.0 & 130.0 & 130.0 & 25.0 & 0.0 & 0.0 & 0.0 & 0.0 & 0.0 & -13.59 & 0.00 & 25.50 & 1103.328 & 1345.6 & 1150.0 & 195.6 \\
\hline 8 & 455.0 & 388.8 & 130.0 & 130.0 & 25.0 & 0.0 & 0.0 & 0.0 & 0.0 & 0.0 & 28.48 & 17.14 & 25.50 & 1082.973 & 1360.5 & 1200.0 & 160.5 \\
\hline 9 & 455.0 & 431.9 & 130.0 & 130.0 & 250 & 20.0 & 25.0 & 0.0 & 0.0 & 0.0 & 26.48 & 31.50 & 25.14 & 1234.730 & 1523.5 & 1300.0 & 223.5 \\
\hline 10 & 455,0 & 455,0 & 130,0 & 130.0 & 87.7 & 20.0 & 25.0 & 10.0 & 0.0 & 0.0 & 25.63 & 36.18 & 25.41 & 1322.868 & 1577.6 & 1400.0 & 177.6 \\
\hline 11 & 455.0 & 455.0 & 130.0 & 130.0 & 124.5 & 20.0 & 25.0 & 10.0 & 10.0 & 0.0 & 27.08 & 38.31 & 25.01 & 1367.224 & 1634.1 & 1450.0 & 184.1 \\
\hline 12 & 455.0 & 455.0 & 130.0 & 130.0 & 148.3 & 20.0 & 25.0 & 10.0 & 10.0 & 10.0 & 46.41 & 35.39 & 24.88 & 1412.925 & 1708.4 & 1500.0 & 208.4 \\
\hline 13 & 455.0 & 455,0 & 130,0 & 130.0 & 98.2 & 20.0 & 25,0 & 10.0 & 0.0 & 0.0 & 14.78 & 36.85 & 25.13 & 1325.569 & 1566.8 & 1400.0 & 166.8 \\
\hline 14 & 455.0 & 429.2 & 130.0 & 130.0 & 25.0 & 20.0 & 25.0 & 0.0 & 0.0 & 0.0 & 28.93 & 31.84 & 25.07 & 1228.074 & 1525.9 & 1300.0 & 225.9 \\
\hline 15 & 455,0 & 419.5 & 130,0 & 130.0 & 25.0 & 0,0 & 0.0 & 0.0 & 0.0 & 0.0 & 10.34 & 9.72 & 20.42 & 1152.787 & 1342.3 & 1200.0 & 142.3 \\
\hline 16 & 455.0 & 298.5 & 130.0 & 130.0 & 25.0 & 0.0 & 0.0 & 0.0 & 0.0 & 0.0 & -16.30 & 12.87 & 14.87 & 911.372 & 1348.3 & 1050.0 & 298.3 \\
\hline 17 & 455.0 & 246.0 & 130.0 & 130.0 & 25.0 & 0.0 & 0.0 & 0.0 & 0.0 & 0.0 & -11.09 & 0.00 & 25.01 & 835.018 & 1343.1 & 1000.0 & 343.1 \\
\hline 18 & 455.0 & 359.4 & 130.0 & 130.0 & 25.0 & 0.0 & 0.0 & 0.0 & 0.0 & 0.0 & -18.77 & 0.00 & 19.29 & 1021.514 & 1350.8 & 1100.0 & 250.8 \\
\hline 19 & 455.0 & 362.1 & 130.0 & 130.0 & 250 & 20.0 & 25.0 & 0.0 & 0.0 & 0.0 & 27.55 & 0.00 & 25.41 & 1078.784 & 1524.5 & 1200.0 & 324.5 \\
\hline 20 & 455.0 & 455.0 & 130.0 & 130.0 & 116.3 & 20.0 & 25.0 & 0.0 & 10.0 & 0.0 & 40.33 & 0.00 & 18.27 & 1333.992 & 1592.3 & 1400.0 & 192.3 \\
\hline 21 & 455.0 & 446.8 & 130.0 & 130.0 & 25.0 & 20.0 & 25.0 & 0.0 & 0.0 & 0.0 & 42.74 & 0.00 & 25.50 & 1271.883 & 1539.7 & 1300.0 & 239.7 \\
\hline 22 & 455.0 & 359.0 & 130.0 & 130.0 & 25.0 & 0.0 & 0.0 & 0.0 & 0.0 & 0.0 & -20.32 & 0.00 & 21.24 & 1020.729 & 1352.3 & 1100.0 & 252.3 \\
\hline 23 & 455.0 & 227.6 & 130.0 & 130.0 & 0.0 & 0,0 & 0.0 & 0.0 & 0.0 & 0.0 & -42.64 & 0,00 & 0.00 & 787.681 & 1212.6 & 900,0 & 312.6 \\
\hline 24 & 455.0 & 150,0 & 110,0 & 127.9 & 0.0 & 0.0 & 0.0 & 0.0 & 0.0 & 0.0 & -45.13 & 0,00 & 2.26 & 697.056 & 1215,1 & 800,0 & 415.1 \\
\hline \multicolumn{18}{|c|}{$\begin{array}{c}\text { Total emission }=24,852.583 \text { tons } \\
\text { Total running cost }=\$ 553,776.56 \text { (fuel cost plus start-up cost) }\end{array}$} \\
\hline
\end{tabular}

Notes: ${ }^{1}$ Wind and solar power forecasting error is $\pm 4 \% ;{ }^{2}$ demand does not include the load of GVs; positive and negative values of V2G/G2V indicate discharging and charging respectively.

TABLE VII

SUMMARY OF INPUT DATA AND RESUlTS OF 10-UNIT SySTEM IN CPES

\begin{tabular}{|c|c|}
\hline Item & Value \\
\hline \multicolumn{2}{|l|}{ Transportation sector } \\
\hline Average distance covered by a vehicle & $12,000 \mathrm{miles} / \mathrm{year}$ \\
\hline Number of registered GVs & 50,000 \\
\hline Average distance covered by GVs per $\mathrm{kWh}$ & 4.00 miles \\
\hline Energy needed by a GV per day & $8.22 \mathrm{kWh}$ \\
\hline Energy needed by $50,000 \mathrm{GVs}$ per day & $411 \mathrm{MWh}$ \\
\hline Typical percentage time a GV is parked & $95 \%$ \\
\hline Average emission from a light weight vehicle & $1.2 \mathrm{lb} / \mathrm{mile}$ \\
\hline Emission from 50,000 vehicles in transportation sector per day (year) & 895.010 tons $(326,678.766$ tons $)$ \\
\hline \multicolumn{2}{|l|}{ Intelligent dynamic load leveling model } \\
\hline $\begin{array}{l}\text { Extra emission from power plants to supply energy to } 50,000 \mathrm{GVs} \text { during one } \\
\text { day (year) }\end{array}$ & 491.311 tons $(179,328.515$ tons $)$ \\
\hline $\begin{array}{l}\text { Net emission reduction from power system and transportation sector for } 50,000 \\
\text { GVs per day (year) }\end{array}$ & 403.699 tons $(147,350.251$ tons $)$ \\
\hline \multicolumn{2}{|l|}{ Smart grid model: Capital cost } \\
\hline Extra energy needed for the smart grid model & $750 \mathrm{MWh}$ per day \\
\hline Wind energy and solar energy ratio (location dependent) & $2: 1$ \\
\hline Capital cost of solar power & $\$ 5.0 / \mathrm{W}$ \\
\hline Capital cost of wind power & $\$ 1.0 / \mathrm{W}$ \\
\hline Solar farm size (based on some assumption of average solar insolation) & $40 \mathrm{MW}$ \\
\hline Wind farm size (based on some assumption of average wind speed) & $25.5 \mathrm{MW}$ \\
\hline Total capital investment for RESs in the smart grid model with $50,000 \mathrm{GVs}$ & $\$ 225.5$ million \\
\hline \multicolumn{2}{|l|}{ Smart grid model: Benefits } \\
\hline Emission reduction from power plants for $50,000 \mathrm{GVS}$ and RESs per day (year) & $1,233.589$ tons $(450,259.985$ tons $)$ \\
\hline $\begin{array}{l}\text { Total emission reduction from power plants and transportation sector for } 50,000 \\
\text { GVs and RESs per day (year) }\end{array}$ & 2128.599 tons $(776,938.751$ tons $)$ \\
\hline $\begin{array}{l}\text { Total operational cost reduction from power system and transportation sectors for } \\
50,000 \text { GVs and RESs in CPES per day (year) }\end{array}$ & $\$ 217,687.73(\$ 79,456,021.45)$ \\
\hline
\end{tabular}

per day for the $50000 \mathrm{GVs}$. Thus, the smart grid model can reduce at least $(3,967.73+213,720=) \$ 217687.73$ from power systems and transportation sector every day.

In this model, all the resources, including wind and solar energy, are intelligently scheduled to minimize both cost and emission. Optimization model uses forecasted wind and solar power, and calculates the best wind and solar power dispatch levels. A forecast error of $\pm 4 \%$ is considered in this study. As operation cost of RESs is zero, optimum power level of RESs using PSO is close to the maximum available power of RESs (see Tables $\mathrm{V}$ and VI). From Tables III, IV and VI, emission is reduced almost all the scheduling hours for using RESs and GVs in a smart grid model.

Present capital costs for wind and solar power are about $\$ 1 / \mathrm{W}$ and $\$ 5 / \mathrm{W}$ respectively. So capital investment in power system is at least $\left(\$ 5 * 40.00 * 10^{6}+\$ 1 * 25.50 * 10^{6}=\right) \$ 225.5$ million to get the full advantage of $50000 \mathrm{GVs}$ in CPES. However, it is expected to reduce per watt capital costs of solar and wind power in near future when mass amount of solar panels and wind turbines will be produced. Data and results are summarized as a tabular form in Table VII.

Number of vehicles connected to the grid or amount of power transaction to/from the grid is not directly proportional to the load demand. Smart schedule of vehicles (amount of power transaction for V2G/G2V) depends on non-linear price curves, emission curves, load demand, constraints, fitness function, and balance between cost and emission. An intelligent optimization method can handle these factors efficiently. Fig. 3 shows an intelligent V2G/G2V distribution using PSO for the 10-unit system with 50,000 vehicles in CPES. Most of the vehicles are connected to the grid at 1st, 12th, 20th, and 24th hours because demand is either very high or very low at those hours. V2G takes place from 8th to 15 th hours and again 19th to 21st hours when demand is high. However, G2V happens from 1st to 7th 


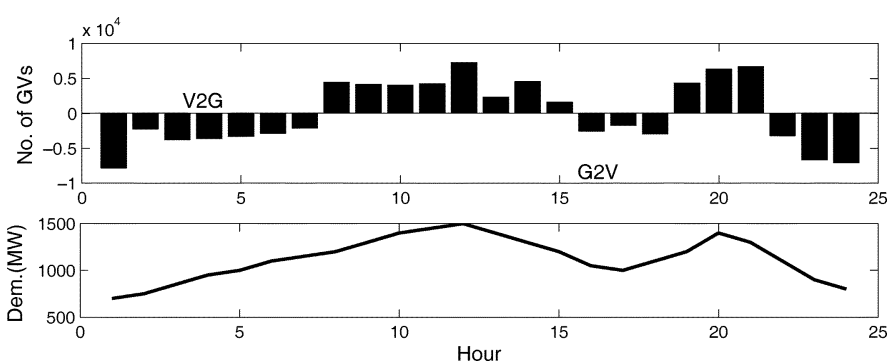

Fig. 3. Number of vehicles for $\mathrm{V} 2 \mathrm{G} / \mathrm{G} 2 \mathrm{~V}$ smart operations at each hour in CPES.

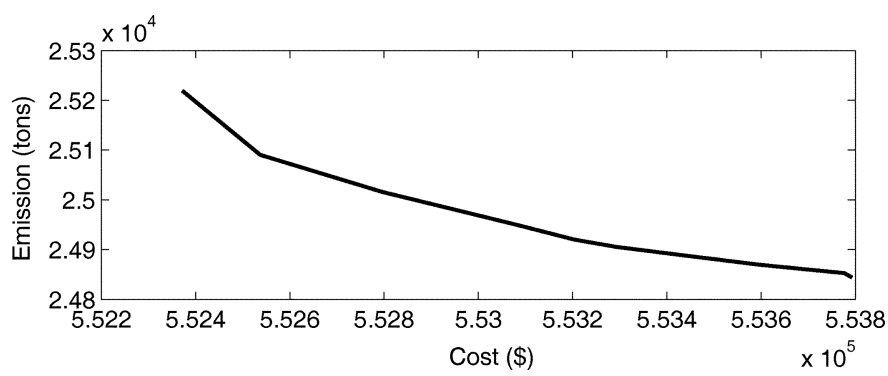

Fig. 4. Nondominated solutions for cost and emission optimization of 10-unit system with RESs and GVs in CPES.

hours, 16th to 18th hours, and 22nd to 24th hours when demand is low.

Fig. 4 shows the relation between cost and emission of the 10-unit system in CPES. There is a trade-off between cost and emission in power system. Results are nondominated to each other, i.e., if cost is low, emission is high, and vice versa. Cost of power generation and corresponding approximate emission can be estimated from the graph. Depending on operator's demand, different weights can be assigned for cost and emission in fitness function (11). Minimum cost is $\$ 552371.58$ where emission is relatively high. On the other hand, minimum emission is 24844.076 tons, where cost is relatively high.

Controllability is already discussed in the end of intelligent load leveling model. The same automatic intelligent agent can be applicable for the smart grid model to control the charging and discharging operations.

\section{CONCLUSION}

A cyber-physical energy system consisting of renewable energy, gridable vehicles and conventional thermal units is presented in this paper. Particle swarm optimization has been applied on dynamic data of physical resources to generate intelligent scheduling and control of green resources, gridable vehicles and conventional thermal units for a sustainable CPES. A sustainable CPES is illustrated by maximum utilization of RESs using GVs for cost and emission reduction. Three possible models have been studied and the smart grid model is a promising approach for sustainable integrated electricity and transportation infrastructure whereas the random mode is more or less not practical. Excess load from gridable vehicles is intelligently distributed to off-peak hours using optimization in the intelligent dynamic load leveling model; however, cost and emission reductions are not enough without RESs, as they are shifted from transportation to power sector. On the other hand, the smart grid model needs considerable amount of capital investment for RESs. As the CPES complexity and shear size evolves, a dynamic method to track the dynamic behavior of RESs and GVs for sustainability is needed. Furthermore, real-time price models have to be considered in the scheduling, control and optimization of gridable vehicles in CPES.

\section{ACKNOWLEDGMENT}

The authors thank the reviewers and the Guest Editor for their constructive comments and suggestions.

\section{REFERENCES}

[1] U. K. Madawala, P. Schweizer, and V. V. Haerri, "Living and mobility- A novel multipurpose in-house grid interface with plug-in hybrid BlueAngle," in Proc. IEEE Int. Conf. Sustainable Energy Technologies (ICSET), Nov. 24-27, 2008, pp. 531-536.

[2] S. Labatt and R. R. White, Carbon Finance: The Financial Implications of Climate Change. Hoboken, NJ: Wiley, 2007.

[3] N. Stern, The Stern Review: The Economics of Climate Change 2006 [Online]. Available: www.sternreview.org.uk

[4] G. K. Venayagamoorthy and G. Braband, "Carbon reduction potential with intelligent control of power systems," in Proc. 17th World Congr., Int. Federation of Automatic Control, Seoul, Korea, Jul. 6-11, 2008.

[5] S. Rahman and B. D. Kroposki, "Photovoltaics - An demand side management performance analysis at a university building," IEEE Trans. Energy Convers., vol. 8, no. 3, pp. 491-497, Sep. 1993.

[6] 20\% Wind Energy by 2030: Increasing Wind Energy's Contribution to U.S. Electricity Supply, [Online]. Available: http://www.eere.energy. gov/windandhydro/pdfs/41869.pdf

[7] K. Parks, P. Denholm, and T. Markel, Costs and Emissions Associated with Plug-In Hybrid Electric Vehicle Charging in the Xcel Energy Colorado Service Territory 2007, Tech. Rep.NREL/TP-640-41410.

[8] Comparing the Benefits and Impacts of Hybrid Electric Vehicle Options for Compact Sedan and Sport Utility Vehicles Electric Power Research Institute, Palo Alto, CA, 2002, EPRI, 1006891.

[9] Barack Obama and Joe Biden: New Energy for America, [Online]. Available: http://www.barackobama.com/pdf/factsheet_energy_speech_080308.pdf

[10] W. Kempton, J. Tomic, S. Letendre, A. Brooks, and T. Lipman, Vehicle-to-Grid Power: Battery, Hybrid and Fuel Cell Vehicles as Resources for Distributed Electric Power in California, Davis, CA Inst. Transportation Studies, 2005, Rep. IUCD-ITS-RR 01-03.

[11] J. Tomic and W. Kempton, "Using fleets of electric-drive vehicles for grid support," J. Power Sources, vol. 168, no. 2, pp. 459-468, Jun. 2007.

[12] W. Kempton and J. Tomic, "Vehicle to grid fundamentals: Calculating capacity and net revenue," J. Power Sources, vol. 144, no. 1, pp. 268-279, Jun. 2005.

[13] W. Kempton and J. Tomic, "Vehicle-to-grid power implementation: From stabilizing the grid to supporting large-scale renewable energy," J. Power Sources, vol. 144, no. 1, pp. 280-294, Jun. 2005.

[14] B. D. Williams and K. S. Kurani, "Estimating the early household market for light-duty hydrogen-fuel-cell vehicles and other "Mobile Energy" innovations in California: A constraints analysis," J. Power Sources, vol. 160, no. 1, pp. 446-453, Sep. 2006.

[15] B. D. Williams and K. S. Kurani, "Commercializing light-duty plug-in/ plug-out hydrogen-fuel-cell vehicles: "Mobile Electricity" technologies and opportunities," J. Power Sources, vol. 166, no. 2, pp. 549-566, Apr. 2007.

[16] W. Kempton and T. Kubo, "Electric-drive vehicles for peak power in Japan," Energy Pol., vol. 28, no. 1, pp. 9-18, 2000.

[17] A. Y. Saber and G. K. Venayagamoorthy, "Intelligent unit commitment with vehicle-to-grid - A cost-emission optimization," J. Power Sources, vol. 195, no. 3, pp. 898-911, Feb. 2010.

[18] T. H. Bradley and A. A. Frank, "Design, demonstrations and sustainability impact assessments for plug-in hybrid electric vehicles," Renew. Sustain. Energy Rev., vol. 13, no. 1, pp. 115-128, Jan. 2009.

[19] G. R. Grob, "Future transportation with smart grids and sustainable energy," in Proc. Int. Multi-Conf. Systems, Signals and Devices, Mar. 23-26, 2009, pp. 1-5.

[20] A. M. Omer, "Energy, environment and sustainable development," Renew. Sustain. Energy Rev., vol. 12, no. 9, pp. 2265-2300, Dec. 2008 
[21] E. O'Neill-Carrillo, A. A. Irizarry-Rivera, J. A. Colucci-Rios, M. Perez-Lugo, and C. Ortiz-Garcia, "Sustainable energy: Balancing the economic, environmental and social dimensions of Energy," in Proc. IEEE Energy2030 Conf., Nov. 17-18, 2008, pp. 1-7.

[22] E. Denny and M. O'Malley, "Wind generation, power system operation, and emissions reduction," IEEE Trans. Power Syst., vol. 21, no. 1, pp. 341-347, Feb. 2006.

[23] P. Venkatesh, R. Gnanadass, and N. P. Padhy, "Comparison and application of evolutionary programming techniques to combined economic emission dispatch with line flow constraints," IEEE Trans. Power Syst., vol. 18, no. 2, pp. 688-697, May 2003.

[24] Y. del Valle, G. K. Venayagamoorthy, S. Mohagheghi, J.-C. Hernandez, and R. G. Harley, "Particle swarm optimization: Basic concepts, variants and applications in Power Systems," IEEE Trans. Evol. Comput., vol. 12, no. 2, pp. 171-195, Apr. 2008.

[25] T. O. Ting, M. V. C. Rao, and C. K. Loo, "A novel approach for unit commitment problem via an effective hybrid particle swarm optimization," IEEE Trans. Power Syst., vol. 21, no. 1, pp. 411-418, Feb. 2006.

[26] C. Roe, A. P. Meliopoulos, J. Meisel, and T. Overbye, "Power system level impacts of plug-in hybrid electric vehicles using simulation data," in Proc. IEEE Energy2030, Atlanta, GA, Nov. 17-18, 2008.

[27] National Renewable Energy Laboratory (NREL) Solar Radiation Research Laboratory (SRRL). Golden, CO [Online]. Available: http:// www.nrel.gov/midc/srrl_bms/

[28] National Renewable Energy Laboratory (NREL) National Wind Technology Center (NWTC). Boulder, CO [Online]. Available: http://www.nrel.gov/midc/nwtc_m2/

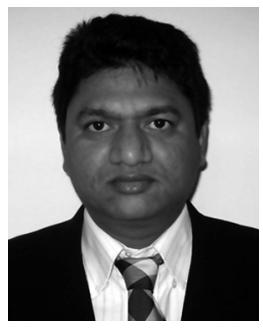

Ahmed Yousuf Saber (M'07) was born in Rajshahi, Bangladesh. He received the B.Sc. and M.Sc. degrees from Bangladesh University of Engineering and Technology, Dhaka, Bangladesh, and the Ph.D. degree from University of the Ryukyus, Okinawa, Japan, in 2007.

Previously, he was a Postdoctoral Fellow with Toyota Technological Institute, Japan, and served as an Assistant Professor at The University of Asia Pacific, Dhaka, Bangladesh, and King Abdulaziz University, KSA. He is currently a Visiting Researcher at the Missouri University of Science and Technology, Rolla. His research interests include smart-grid, vehicle-to-grid, renewable energy, micro-grid, cyber-physical systems, power system optimization, intelligent systems, operations research, and CI applications.

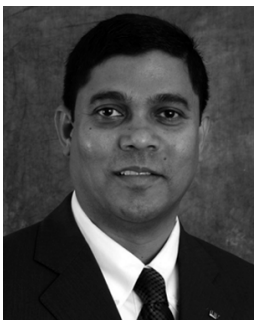

Ganesh Kumar Venayagamoorthy (S'91-M'97SM'02) received the Ph.D. degree in electrical engineering from the University of Natal, Durban, South Africa, in 2002.

Currently, he is an Associate Professor of Electrical and Computer Engineering, and the Founder and Director of the Real-Time Power and Intelligent Systems (RTPIS) Laboratory, at Missouri University of Science and Technology (Missouri S\&T), Rolla. He was a Visiting Researcher with ABB Corporate Research, Vasteras, Sweden, in 2007. His research interests are in the development of advanced computational methods and algorithms for real-world applications, including power systems stability and control, smart grid applications, sensor networks and signal processing. He has published two edited books, six book chapters, and over 85 refereed journals papers and 275 refereed conference proceeding papers. He has been involved in approximately US\$ 7 million of competitive research funding.

Dr. Venayagamoorthy is a recipient of several awards, including a 2007 U.S. Office of Naval Research Young Investigator Program Award, a 2004 U.S. National Science Foundation CAREER Award, the 2010 Innovation Award from the Academy of Science of St. Louis, the 2010 IEEE Region 5 Outstanding Member, the 2008 IEEE St. Louis Section Outstanding Educator Award, the 2006 IEEE Power Engineering Society Walter Fee Outstanding Young Engineer Award, the 2005 IEEE Industry Applications Society (IAS) Outstanding Young Member Award, and the 2003 International Neural Network Society (INNS) Young Investigator Award. He is a Fellow of the Institution of Engineering and Technology (IET), U.K., and the South African Institute of Electrical Engineers, a Senior Member of INNS, and a Member of the American Society for Engineering Education and the INNS Board of Governors. He is a current editorial board member of the new IEEE TRANSACTIONS ON SMART GRID and the IEEE TRANSACTIONS ON EVOLUTIONARY COMPUTATION. 